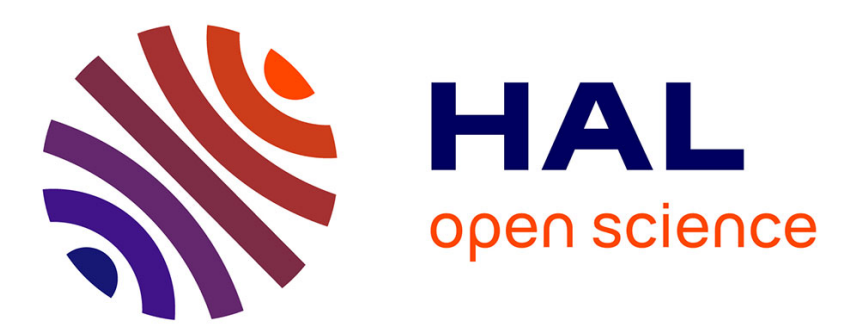

\title{
Seasonal variation in attention and spatial performance in a wild population of the African striped mouse (Rhabdomys pumilio)
}

Audrey Maille, Neville Pillay, Carsten Schradin

\section{- To cite this version:}

Audrey Maille, Neville Pillay, Carsten Schradin. Seasonal variation in attention and spatial performance in a wild population of the African striped mouse (Rhabdomys pumilio). Animal Cognition, 2015, 18 (6), pp.1231-1242. 10.1007/s10071-015-0892-y · hal-01171729

\author{
HAL Id: hal-01171729 \\ https://hal.science/hal-01171729
}

Submitted on 6 Jul 2015

HAL is a multi-disciplinary open access archive for the deposit and dissemination of scientific research documents, whether they are published or not. The documents may come from teaching and research institutions in France or abroad, or from public or private research centers.
L'archive ouverte pluridisciplinaire HAL, est destinée au dépôt et à la diffusion de documents scientifiques de niveau recherche, publiés ou non, émanant des établissements d'enseignement et de recherche français ou étrangers, des laboratoires publics ou privés. 
1 Seasonal variation in attention and spatial performance in a wild 2 population of the African striped mouse (Rhabdomys pumilio).

3

4

5

6

7

8

9

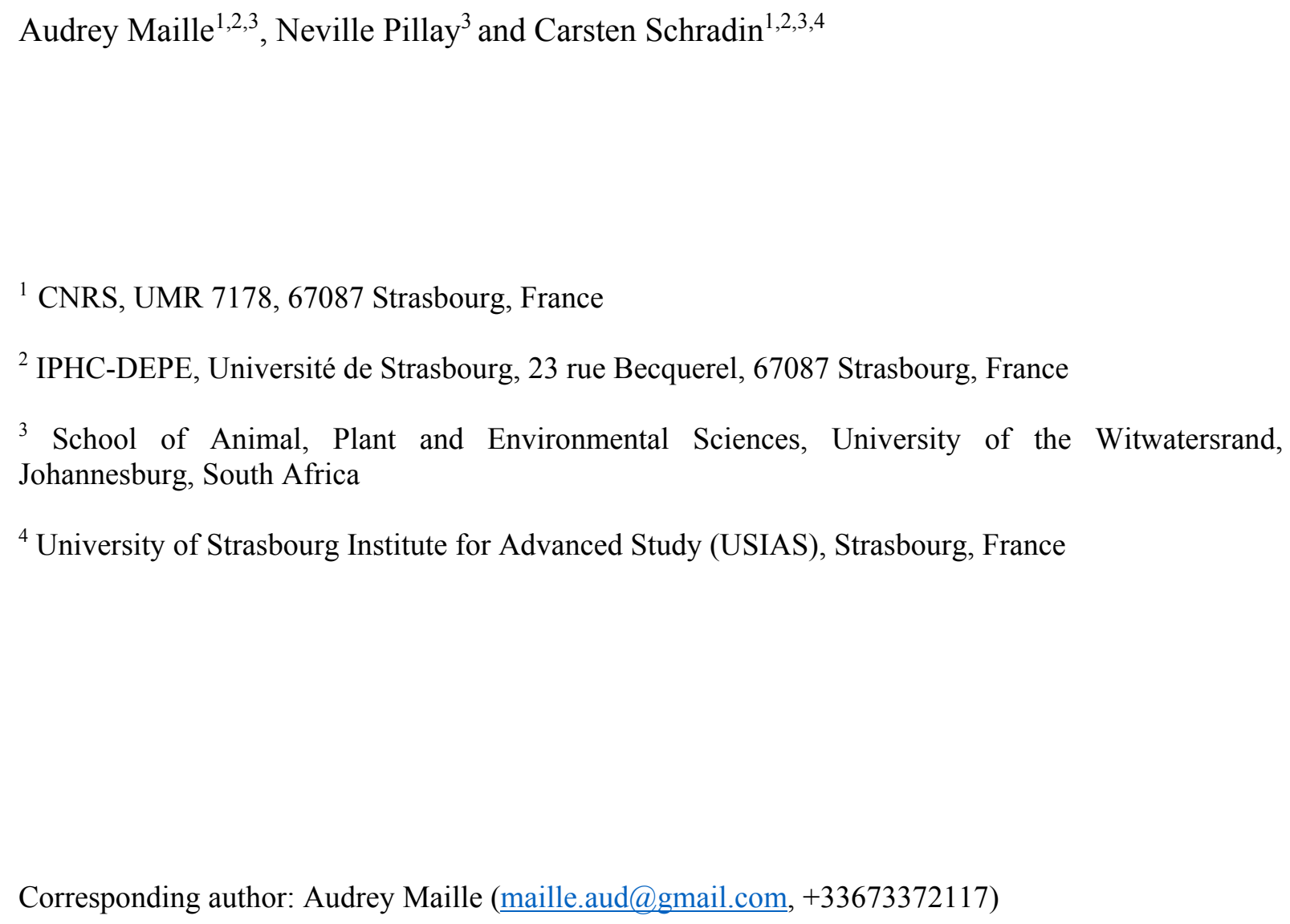




\section{Abstract}

32

33

Cognitive flexibility describes the reversible changes of cognition in response to environmental changes. Although various environmental factors such as temperature, photoperiod and rainfall change seasonally, seasonal variation in cognitive performance has been reported in merely a few birds and mammals. We assessed whether cognitive performance in a wild population of African striped mice Rhabdomys pumilio, from the Succulent Karoo semi-desert of South Africa, differed between summer and winter. In order to measure cognitive performance, striped mice were trapped in the field, tested under laboratory conditions at our research station, and returned to the field within 5 hours. We measured attention and spatial memory using the standardized orientation response test and the Barnes maze test. Males tested during summer oriented faster toward a predator-stimulus but made more errors and took longer to locate a shelter than males tested during winter. In contrast, females' performance did not differ between the two seasons. We discuss how the faster orientation in males during winter might be the consequence of lower temperatures and/or prolonged food restriction. We suggest that the enhancement of spatial performance during winter might be due to a greater motivation for future dispersal in male striped mice, as spring represents the breeding season.

\section{Keywords}

Cognitive flexibility, Seasonality, Orientation response, Spatial memory, Sex differences 
Reversible changes in cognitive performance are defined as cognitive flexibility, which is a particular type of phenotypic flexibility (Piersma and Drent 2003). One example of cognitive flexibility is seasonal variation in cognitive performance, which has been observed in a few bird and mammal species. For instance, song production and learning are increased during the breeding season in passerine birds (Tramontin \& Brenowitz 2000). Moreover, spatial memory of several seasonal breeders is enhanced before the onset of the breeding season, for example in the parasitic birds Molotrus bonariensis and M. rufoaxilaris (Clayton et al. 1997) and in dispersing rodents such as deer mice Peromyscus maniculatus (Galea et al. 1994) and P. leucopus (Pyter et al. 2006) and voles Microtus pennsylvanicus (Galea et al. 1996) and Clethrionomys glareolus (Yaskin 2013). In contrast, spatial memory of food-caching birds improves in winter (Sherry and Hoshooley 2009). Interestingly, in some of these species, there is also evidence of seasonal variation in the volume of the brain structures controlling song production (i.e. song control nuclei: Tramontin \& Brenowitz 2000) and spatial memory (i.e. hippocampus: Clayton et al.. 1997; Galea and McEwen 1999).

Cognitive performance might be enhanced under harsh seasonal conditions as an adaptation to meet specific ecological needs (Buchanan et al. 2013). For example, improved cognition might help an individual to face changes in food availability. Food restriction (i.e. low availability and/or predictability) leads to improved learning in cichlid fish Simochromis pleurospilus (Kotrschal and Taborsky 2010), mountain chickadees Poecile gambeli (Pravosudov and Clayton 2001), rats Rattus rattus (Aimé et al. 2007) and mouse lemurs Microcebus murinus (Dal-Pan et al. 2011). Predation risk is another factor affecting learning. For example, in tadpoles, short exposure to predatory cues induces a stronger defense response (i.e. lower activity level) and longer memory retention to a predator stimulus (Ferrari 2014). Alternatively, cognitive performance might be impaired under harsh seasonal conditions because of a need to reduce energy-demanding physiological processes, including cognition. Cognitive processing is energetically costly because the development of the underlying neuronal structures requires neurogenesis (Isler and van Schaik 2006), synaptic formation (Roth et al. 2010), and the generation and propagation of neuronal signals (Gilsenan et al. 2009). The cost of maintaining or even improving cognitive performance is thus expected to be of particular importance for individuals experiencing extreme environmental harshness (Laughlin 2001). In sum, although seasonal environmental changes are expected to influence cognition, to date, few studies have tested whether cognition is maintained, impaired, or improved during the harshest season.

There are a number of factors, such as food availability and photoperiod, that are associated with the change of seasons and may serve as environmental cues leading to changes in cognitive functions. One important factor that changes seasonally in most environments is ambient temperature. Maintaining a 
constant body temperature is energetically highly expensive for endotherms, especially for smaller bodied species, such as rodents (Canals et al. 1989). Numerous studies have demonstrated that the basal metabolic rate increases as the ambient temperature drops (e.g. Geiser 2004). In addition, endotherms face the necessity to invest more energy into thermoregulation in environments where ambient temperatures fall clearly below their thermoneutral zone (i.e. range of ambient temperatures at which the metabolic cost of maintaining body temperature is minimal). Individuals living in energy restricted environments are expected to trade-off between investing energy either into cognition or into other life sustaining processes, such as thermoregulation (Maille and Schradin, submitted). Increased thermoregulatory costs could thus affect the energy available for cognitive processing, especially in animals with a high surface : volume ratio, such as rodents. In the current study, we aimed to establish whether a seasonal decrease in ambient temperature would lead to lower cognitive performance in a free-living population of rodents. In the northern hemisphere, the cold season is also a season of low food availability which leads to the difficulty of disentangling the influence of seasonal changes in food availability versus ambient temperature on cognitive performance. To study the effect of ambient temperature independent of food availability, one would need a study system where the ambient temperature changes seasonally but food availability does not.

We assessed cognitive performance in a wild population of African striped mice Rhabdomys pumilio, living in a semi-desert characterized by pronounced seasonal changes in ambient temperature. This rodent species is a good model to study cognitive flexibility in free ranging mammals because sample sizes are large, it is diurnal, which enables behavioural testing during the day, and it can be tested using standardized cognitive procedures for laboratory rodents, offering a high degree of control (e.g. Rymer et al. 2008; Pillay and Rymer 2015). We focused on cognitive traits important for a small diurnal rodent living in an open environment to avoid predators (Abrams 1994). First, we assessed attention in a simulated predation event (appearance of an image of a bird of prey). Second, we studied spatial memory because learning the locations of safe shelters is crucial for prey to escape predators. We compared the cognitive performance of striped mice tested either during summer (hot ambient temperature) or during winter (cold ambient temperature), using two standardized laboratory tests, the orientation response test (i.e. measurement of attention: Rodriguiz and Wetsel 2006) and the Barnes maze test (i.e. measurement of spatial learning and memory: Barnes 1979).

The environmental conditions occurring during the study enabled us to assess the influence of seasonal changes in temperature on cognitive performance of striped mice, while food availability remained relatively stable. In the year of the study, temperatures dropped from $9{ }^{\circ} \mathrm{C}$ at night in the austral summer to $1{ }^{\circ} \mathrm{C}$ at night in the austral winter, in both cases being clearly below the striped mouse thermoneutral zone of $31{ }^{\circ} \mathrm{C}$ (Scantlebury et al. 2006). However, food plant density remained low during both seasons because winter precipitation, characteristic of our study site in the Succulent 
Karoo, arrived very late (in June that is 2 months later than usual). The striped mice that were tested thus experienced a 6-month period of low food availability. We assumed that striped mice faced a greater need to trade-off energy allocation for cognition in winter, because of the prolonged period of low food availability coupled with the increased energetic costs of thermoregulation. We therefore predicted a reduction in cognitive performance of striped mice from summer to winter.

\section{Material and methods}

\section{Study species}

We studied a population of African striped mice Rhabdomys pumilio living in the Succulent Karoo of South Africa. Social groups of striped mice (2-30 adult individuals of both sexes) share one nest and territory but forage solitarily (Schradin 2006). Striped mice do not usually breed in the year of their birth but do so in the following year when they are 10-12 months old (Schradin and Pillay 2005). All individuals tested were born during the previous breeding season (i.e. that takes place in austral spring: September to November; Schradin and Pillay 2005).

\section{Study area and period}

142

The study was conducted in Goegap Nature Reserve, near Springbok in the Northern Cape Province, South Africa (S 29 41.56, E 18 1.60; for pictures of the field site see www.stripedmouse.com). The area is semi-arid, with an average annual rainfall of $160 \mathrm{~mm}$ p.a. (Rosch 2001). The vegetation type is classified as Succulent Karoo (Cowling et al. 1999). The study area of 5 ha was occupied by 14 groups of striped mice. Group association of individual mice was determined by trapping, radio-tracking and behavioural observations of nesting sites during mornings and afternoons (Schradin and Pillay 2005). The study took place from $17^{\text {th }}$ January to $8^{\text {th }}$ July 2014 . The weather was hot and dry during the austral summer months of the study $\left(17^{\text {th }}\right.$ January to $8^{\text {th }}$ April: average temperature $\pm \mathrm{SE}=25.1 \pm 2.0$ ${ }^{\circ} \mathrm{C}$, total rainfall $=35 \mathrm{~mm}$ p.a.) whereas a drop in temperature occurred during the austral winter months $\left(15^{\text {th }}\right.$ May to $8^{\text {th }}$ July: average temperature $\pm \mathrm{SE}=14.6 \pm 1.4{ }^{\circ} \mathrm{C}$, total rainfall $=46 \mathrm{~mm}$ p.a., Table 1).

Striped mice mainly feed on plants (>99\%) and plant surveys were conducted on the $1^{\text {st }}$ and on the $15^{\text {th }}$ of each month at our field site, using the Braun-Blanquet Method. The number of food plants species (palatability known from behavioural observations; Schradin \& Pillay 2006) was recorded in each of eight monitoring plots of $2 \times 2 \mathrm{~m}$. Food availability for the striped mice remained relatively stable within the study period and population size only decreased slightly from summer to winter (Table 1). 
162 Cognitive tests were performed on 105 adult mice from nine different groups: 59 mice (30 males, 29

163 females) were tested in summer from $17^{\text {th }}$ January to $8^{\text {th }}$ April and 46 mice (26 males, 20 females)

164 were tested in winter from $15^{\text {th }}$ May to $8^{\text {th }}$ July. None of the individuals was tested in both seasons to avoid any learning effect.

\section{Trapping and marking}

168 Striped mice were trapped directly at their nests by using metal live traps similar to Sherman traps (26 $169 \times 9 \times 9 \mathrm{~cm}$ ) baited with a mixture of bran flakes, raisins, oil and sea salt. Traps were placed in the 170 shade under bushes where the mice had been nesting the night before. Individuals were permanently 171 marked using numbered metal ear tags (National Band and Tag Co., Newport, KY, USA). 172 Additionally, each individual was marked on the pelage for visual identification by using commercial 173 hair dye (Rapido, Pinetown, South Africa). All methods followed standard protocol and have been used successfully on striped mice since 2001 (Schradin and Pillay 2005).

\section{Body mass and metabolism}

177 We measured body mass and performed blood sampling 5 to 20 days before cognitive testing to be 178 able to measure metabolic indicators (glucose, ketone and corticosterone) while at the same time 179 giving the mice enough time to rest between blood sampling and cognitive testing. Striped mice were 180 trapped early in the morning before they left their nest to forage in order to obtain measurements after the overnight fast and before onset of foraging and pronounced physical activity. As soon as a mouse entered a trap it was anaesthetized with diethyl ether and approximately $400 \mu \mathrm{L}$ of blood was obtained from a sub-lingual vein. Blood glucose and ketone bodies were directly measured using the One Touch Ultra glucometer (Lifescan, Inc., Milpitas, CA, USA) and the Freestyle Optium Blood $\beta$ Ketone meter (Abbott Laboratories, Australia). Samples were collected within a 3 minutes delay and were transported to the research station where they were centrifuged twice for 10 minutes in order to obtain serum. Alliquots were stored at $-20^{\circ} \mathrm{C}$ and later analysed at the Institut Pluridisciplinaire Hubert Curien using a validated commercial kit from IBL Hamburg.

\section{Cognitive testing}

191 Each morning, 2 to 3 striped mice were trapped at their nest within the first hour after sunrise and brought to a research room located a 5-minute walking distance from the field site. Tests were performed in a specific laboratory room $(3.70 \times 3.10 \times 2.40 \mathrm{~m})$ constructed for this project. The laboratory room was split into two areas with a black non-translucent curtain hanging from the ceiling, one area being used for testing the mice (testing area: $1.60 \times 3.10 \times 2.40 \mathrm{~m}$ ) and the other area to serve as a hide for the experimenter. The temperature inside the laboratory room was not controlled and tracked the ambient outdoor temperatures (no heater used in winter). Individuals were first tested for 
the orientation response test (description below), lasting 10 minutes. Following an interval of 1 to 2 hours during which mice were placed individually in a quiet room in a plastic cage $(22 \times 16.5 \times 14$ $\mathrm{cm})$ with sand for bedding and an egg box as shelter, mice were brought back to the laboratory and tested in the Barnes maze test (description below), lasting 60 to 90 minutes. After testing, mice were given 10 sunflower seeds to compensate for missed foraging opportunities, and were then released at their nest in the field site.

\section{Orientation response test}

The Orientation response test uses the natural propensity of rodents to orient their head or whole body toward a salient stimulus (Rodriguiz and Wetsel 2006). A mouse was placed in a perspex box (18.5 x $13 \times 11.5 \mathrm{~cm})$ that was centered in a black plastic chamber $(57 \times 38 \times 25 \mathrm{~cm})$. The lid and one lateral side of the box were transparent whereas the other sides had been made opaque using black tape. The transparent lateral side of the box faced a computer screen $(7$ inches $=15 \times 9.5 \mathrm{~cm}$; distance box to screen: $17 \mathrm{~cm}$ ) connected to a laptop (Online Resource 1). After a 5 minute familiarization to the setup during which the mouse was exposed to a white screen, a raptor-stimulus was projected onto the screen. The raptor-stimulus was a photo of flying jackal buzzard Buteo rufofuscus, a natural predator of the striped mouse, presented in a horizontal sliding motion (Online Resource 1). The raptorstimulus presentation was repeated 10 times, once every 25 seconds, each presentation lasting 5 seconds. To reduce habituation to the raptor-stimulus, a different starting location on the screen was used for each presentation. In addition, the raptor-stimulus moved either leftward or rightward (5 presentations each). Mice were videotaped using a high speed Casio camera EX-ZR200 recording at 120 frames/second. Light for videotaping was provided by a $11 \mathrm{~W}$ lamp mounted above the set-up. For each presentation, we recorded whether the mouse showed an orientation response toward the raptorstimulus and the time for the mouse to start orienting toward the raptor-stimulus. We considered that a mouse showed an orientation response when it turned its head towards the raptor-stimulus.

\section{Barnes maze test}

The Barnes maze test (Barnes 1979) measures spatial learning and memory by assessing the ability of rodents to relocate a hole giving access to a shelter among numerous available holes. The maze consisted of a circular platform $110 \mathrm{~cm}$ in diameter raised $60 \mathrm{~cm}$ from the ground (Online Resource 2). The maze was surrounded by a $30 \mathrm{~cm}$ high transparent perspex cylinder because striped mice, unlike laboratory mice and rats, would otherwise have jumped off the platform. The platform was made of white perspex bored with 12 equidistant circular holes $5 \mathrm{~cm}$ in diameter and $7 \mathrm{~cm}$ from the outer edge (Online Resource 2). One hole provided access to a dark escape box underneath (15 x $13 \mathrm{x}$ $9 \mathrm{~cm}$ ) but the 11 remaining holes were closed with black PVC panels made of the same perspex as the escape box (15 x $13 \times 0.1 \mathrm{~cm}$, placed under the holes). To provide visual landmarks for the mice, we placed 6 pictures of rocks or plants from the field site on the walls and curtains surrounding the set-up, 
$50 \mathrm{~cm}$ above the platform of the Barnes maze (mice could see the landmarks whatever their location in the maze; Online Resource 2).

Individuals were tested for 2 sessions, the second session (i.e. long-term memory session) occurring 8 \pm 3 days after the first session (i.e. short-term memory session). The mice were released into the field after the first session and were re-trapped before the second session. Each session consisted of 9 trials separated by a 5-minute delay during which the maze and escape box were cleaned using $70 \%$ alcohol and the mouse was transferred from the escape box to the starting box. Trials were always conducted in the same order: 6 neutral trials N1 to N6 (i.e. with the escape box) that were followed by 2 bat trials $\mathrm{B} 1$ and B2 (i.e. with the escape box and a bat toy hanging above the maze) and finally a control trial C (i.e. no escape box and no bat toy). During the bat trials, an automated flapping battery run bat-like toy (Out of the Blue KG, Germany) was hung $120 \mathrm{~cm}$ above the maze to mimic a bird of prey; striped mice were very wary and quickly looked for shelter when exposed to this toy (Online Resource 2). During the control trial, the escape box was replaced by a black PVC panel to control for the use of visual and olfactory cues from the escape box.

Before each trial, a mouse was placed in a circular and transparent starting box (diameter $=10 \mathrm{~cm}$, height $=10 \mathrm{~cm}$ ) in the center of the Barnes maze. The mouse was able to see the holes from the center of the arena but not which one was the correct hole giving access to the escape box. A trial started when the mouse was released from the starting box that was lifted by pulling a string attached to the box (Online Resource 2). To reduce disturbance of the tested mouse, the experimenter pulled the string from behind the curtain. The neutral and bat trials ended when the mouse entered the escape box. When the mouse did not enter the escape box within 5 minutes, the experimenter gently led the mouse to the correct hole and encouraged it to enter the box. The control trial ended when the mouse poked the correct hole.

The location of the correct hole was randomly determined for each mouse and remained constant for all the trials and sessions for that individual mouse. Mice were videotaped using a Microsoft HD webcamera connected to a laptop. For each trial, we recorded the number of errors (i.e. poke into another hole than the correct hole) before the mouse nose-poked the correct hole and the latency to nose-poke the correct hole. We considered that a mouse poked a hole when it placed its nose inside the hole or less than $1 \mathrm{~cm}$ away from the hole, the head being oriented toward the hole. A second observer coded $5 \%$ of the videos ( 86 randomly selected videos): the weighted Cohen's kappa coefficient of agreement between the two observers was 0.86 . 
273 All statistics were performed with $\mathrm{R}$ v. 3.0.2 (The $\mathrm{R}$ foundation for statistical computing, 274 http://www.r-project.org/). Mixed models were constructed using the lmer function in Ime4 package.

275

276

277

278

279

280

281

282

283

284

285

286

287

288

289

290

291

292

293

294

295

296

297

298

299

300

301

302

303

304

305

306

307

308

Attention in the Orientation response test

Seasonal differences in attention were analyzed by performing two linear mixed models, one with number of orientation responses and the other with orientation time as dependent variable, and sex and season specified as fixed effects. We specified group identification as a random factor to control for potential confounding effects of group origin (litter and/or ecology). To obtain normality of residuals, data were transformed using a logarithm +1 transformation for the number of orientation responses and a logarithm transformation for the orientation time.

\section{Spatial memory in the Barnes maze test}

We initially assessed whether spatial memory performance changed during the consecutive trials and sessions of the Barnes maze test. Differences in spatial memory were analyzed by performing two linear mixed models, one with number of errors and the other with latency to poke the correct hole for each trial as the dependent variable, trial and session as fixed effects, and ID number of the mice as random factor (i.e. repeated measures design).

For each session of the Barnes maze test, seasonal differences in spatial memory were analyzed by performing two linear mixed models, with either number of errors or latency to poke the correct hole as the dependent variable, season (i.e. summer and winter), sex and category of trials (i.e. N-I, N-II, B and $\mathrm{C}$; see results for description) specified as fixed effects, and ID number of the mice as random factor (i.e. repeated measures design). To control for potential confounding effects of group origin of the striped mice and location of the correct hole in the BM test, we constructed mixed models with group identifications and the number of the correct hole specified as random factors. To obtain normality of residuals, data were transformed using a logarithm +1 transformation for the number of errors and a logarithm transformation for the latency. In our study, we could not exclude age as a confounding factor in our analyses because the individuals tested during winter were a few months older than those tested during summer.

\section{Results}

\section{Seasonal variation in body condition}

The body mass and the blood glucose and ketone bodies levels did not differ between individuals tested in summer or in winter (t-test: $p>0.05$, Table 2), indicating that energy balance (energy intake 
- energy expenditure) did not change between the two seasons (McCue 2010). Basal corticosterone levels decreased from summer to winter (t-test: $p=0.011$, Table 2), which is supposed to reduce energy expenditure to enable individuals to cope with long periods of low food availability (Romero 2002).

\section{Seasonal variation in attention (Orientation response test)}

\section{Number of orientation responses}

We excluded 11 males (summer: $\mathrm{N}=6$, winter: $\mathrm{N}=5$ ) and 6 females (summer: $\mathrm{N}=4$; winter: $\mathrm{N}=2$ ) from the analyses because they never reacted to the raptor-stimulus within the 10 presentations. There was no difference between summer and winter in the proportions of individuals that never oriented or oriented to the raptor-stimulus (Fisher exact test: males $p=0.744$, females: $p=0.684$ ). There was no significant seasonal effect on the number of orientation responses to the raptor-stimulus $(\chi 2=0.32, p=$ $0.572)$ and no significant interaction between season and $\operatorname{sex}\left(\chi^{2}=0.01, \mathrm{p}=0.946\right)$.

\section{Orientation time}

Striped mice tested during winter tended to orient more slowly toward the raptor-stimulus than mice tested during summer $(\chi 2=3.53, p=0.060)$. Although the interaction between season and sex was not significant $\left(\chi^{2}=1.74, \mathrm{p}=0.187\right)$, we found that the males tested during winter were significantly slower to orient towards the raptor-stimulus than the males tested during summer (t-tests: $p=0.037$ ) while there was no difference for females (t-tests: $p=0.670$; Fig. 1).

\section{Seasonal variation in spatial memory (Barnes maze test)}

Whatever the session, the number of errors and latency to poke the correct hole did not differ between the control trial C and the last neutral trial N6 (pairwise-t-test: $\mathrm{p}>0.05$, Fig. 2) which indicates that mice did not use olfactory or visual cues from the escape box to locate the correct hole. The latency to poke the correct hole was significantly greater in the control trial than in the last bat trial B2 (pairwiset-test: short-term session: $p<0.05$, Fig. 2 ) though the number of errors did not significantly differ between these two trials (pairwise-t-test: short-term session: $p>0.05$, Fig. 2).

Spatial memory performance significantly differed between the short-term memory session and the long-term memory session (number of errors (E): $\chi^{2}=81.44, \mathrm{p}<0.001$; latency (L): $\chi^{2}=180.88, \mathrm{p}<$ $0.001)$ and among the 9 trials $\left(\mathrm{E}: \chi^{2}=273.18, \mathrm{p}<0.001\right.$; L $\left.\chi^{2}=476.09, \mathrm{p}<0.001\right)$. Because the analyses also revealed significant interactions between sessions and trials $\left(\mathrm{E}: \chi^{2}=49.38, \mathrm{p}<0.001\right.$; L: $\chi^{2}=21.72, p=0.005$ ), we decided to perform all the subsequent statistical analyses for the two sessions separately. 
347 To reduce the number of multiple comparisons, we grouped the N1 and N2 trials into a "neutral-I 348 trials" (N-I) category, the N3 to N6 trials into a "neutral-II trials" (N-II) category and the B1 and B2 349 trials into a "bat trials" (B) category based on significant differences between trials in the short-term 350 memory session (t-tests: $\mathrm{p}<0.05$ : see Fig. 2). Within each category, there were no differences 351 between trials for either the number of errors (except in the N-I category) or the latency to poke the 352 correct hole.

353

354

355

356

357

358

359

360

361

362

363

364

365

366

367

368

369

370

371

372

373

374

375

376

377

378

379

380

381

382

\section{Short-term memory-session}

For the short-term memory session, there was no significant seasonal effect on either the number of errors $\left(\mathrm{E}: \chi^{2}=0.00, \mathrm{p}=0.966\right)$ nor the latency to poke the correct hole $\left(\mathrm{L}: \chi^{2}=0.73, \mathrm{p}=0.392\right)$. Regarding the number of errors, the analysis revealed no significant interaction between season and category of trials $\left(\mathrm{E}: \chi^{2}=0.33, \mathrm{p}=0.850\right)$ and no significant interaction between sex, season and category of trials $\left(\mathrm{E}: \chi^{2}=0.91, \mathrm{p}=0.823\right.$ ). In contrast, regarding the latency to poke the correct hole, the analysis revealed significant interactions between the sex and the category of trials $\left(\mathrm{L}: \chi^{2}=18.21\right.$, $\mathrm{p}<0.001$ ) and between the season, sex and category of trials ( $\mathrm{L}: \chi^{2}=10.92, \mathrm{p}=0.012$, Fig.3). We thus analyzed the influence of the season on the latency to poke the correct hole for each category of trials and for males and females separately.

Males tested during winter poked the correct hole significantly faster in the Control trial than males tested during summer ( $t$-tests: Control: $p=0.019$ ), whereas there were no differences for the other categories of trials (t-tests: N-I: $p=0.280$; N-II: $p=0.470$, Bat: $p=0.540$; Fig. 3). Females did not differ between seasons in their latency to poke the correct hole, whatever the category of trials (t-tests: N-I: $p=0.730$, N-II: $p=0.530$, Bat: $p=0.580$, Control: $p=0.410$; Fig. 3).

\section{Long-term memory-session}

For the long-term memory session, the analyses revealed a significant interaction between sex, season and category of trials for both the number of errors and the latency to poke the correct hole (E: $\chi^{2}=$ $30.68, p<0.001$; L: $\chi 2=7.97, p=0.047$, Fig. 3). We thus analyzed the influence of the season on the number of errors and the latency to poke the correct hole for each category of trials and for males and females separately.

Males tested during winter made significantly fewer errors in the Neutral-II category than males tested during summer ( $t$-tests: $N-I I: p=0.009)$ whereas there were no differences for the other categories ( $t$ tests: N-I: $p=0.480$; Bat: $p=0.720$, Control: $p=0.560$; Fig. 4a). Males tested during winter poked the correct hole significantly faster in the Neutral-II and Control category than males tested during summer (t-tests: N-II: $p<0.001$, Control: $p=0.011$ ) whereas there were no differences for the other 
categories (t-tests: N-I: $p=0.290$, Bat: $p=0.500$; Fig. $4 \mathbf{b}$ ). In contrast, whatever the category of trials, females tested during winter did not differ from those tested during summer for either the number of errors (t-tests: N-I: $\mathrm{p}=0.150, \mathrm{~N}-\mathrm{II}: \mathrm{p}=0.270$, Bat: $\mathrm{p}=0.380$, Control: $\mathrm{p}=0.810$; Fig. 5a) or the latency to poke the correct hole (t-tests: N-I: $p=0.940, N-I I: p=0.290$, Bat: $p=0.890$, Control: $p=$ 0.810 ; Fig. 5b).

\section{Discussion}

We assessed cognitive performance in attention and spatial memory in a free-living population of African striped mice Rhabdomys pumilio that experienced seasonal changes in ambient temperature while food availability remained relatively stable. Males tested during summer oriented faster toward a predator-stimulus in an orientation response test but made more errors and took longer to locate the shelter in some (but not all) trials of a Barnes maze test compared to males tested during winter. Thus, the performance of males declined from summer to winter in a test assessing attention whereas they improved from summer to winter in a test assessing spatial learning and memory. In contrast, the performance of females did not differ between the seasons. Multiple potential proximate as well as ultimate factors can be put forward to explain these results.

Although seasonal variation in attention of male African striped mice must be interpreted with caution (because of a non-significant interaction between the sex and the season), males tested in winter were slower to orient toward the predator-stimulus in the orientation response test than males tested in summer. The increased orientation time of males tested in winter might be a consequence of seasonal changes in ambient temperature. Ambient temperature has a significant effect on the activity of striped mice, which use sun-basking to warm up especially when mornings are cold (Schradin et al. 2007), thereby reducing their energy expenditure (Scantlebury et al. 2010). The importance of sun-basking for thermoregulation and energy balance has been considered for diverse small mammals taxa (Geiser et al. 2002). Moreover, ambient temperature can be related to cognition in both birds and mammals. For example, short-term decrease in ambient temperatures affects foraging decisions in European starling Sturnus vulgaris (Chatelain et al. 2013) and induces both motor and cognitive impairment in humans (Solianik et al. 2014). Indeed, human reaction time is longer in cold environmental conditions, men being more affected by low temperatures than women (Solianik et al. 2014). Such sex differences in reaction time in response to cold might explain why only male striped mice were slower to orient toward a predatory-stimulus when tested during winter (low temperatures) compared to summer (high temperatures). However, we cannot exclude the possibility that orientation time of male striped mice may have been influenced by at least two other proximate factors than the ambient temperature. First, attention of male striped mice might be influenced by the photoperiod (daylight length). Photoperiod is usually a highly reliable cue in predictable environments, enabling individuals to respond to

\section{$12 \mid 21$}


seasonal changes (Yaskin 2011). For example, marsh tits Parus palustris that cache food during winter perform better in spatial learning during short compared to long daylight cycles (Clayton and Cristol 1996). However, we believe that photoperiod does not determine the attentional variation that we reported in male striped mice because photoperiod is not a reliable cue for seasonal changes in rainfall and consequently food availability in the Succulent Karoo. This lack of predictability may explain why food availability itself and not photoperiod regulates hormone secretion and reproduction in striped mice (Raynaud and Schradin 2013). Second, the increase in orientation time from summer to winter in male striped mice may alternatively be the consequence of prolonged food restriction within the study period, lasting from January to July. Cognitive impairments were reported in rats that had experienced at least 5 months of food restriction (Yanai et al. 2004). Since stress-induced changes in cognition are often sexually differentiated (Bowman 2005), the negative influence of prolonged food restriction on orientation time may have been more pronounced in males than females in the African striped mouse.

At the evolutionary level, seasonal cognitive flexibility in attention might have an adaptive value in species facing seasonal changes in predation risk. Faster detection of predators during summer in male striped mice may have evolved in response to the higher predation pressure that probably occurs in this season because of high predator density (i.e. most predators of striped mice reproduce in late spring, leading to high population densities of predators in summer).

Striped mice showed spatial learning and long-term memory in the Barnes maze test, similar to other rodent species, such as deer mice Peromyscus maniculatus and P. californicus (Jašarević et al. 2012) and Octodon degus (Popović et al. 2010). Surprisingly, seasonal variation in spatial performance were opposite to our predictions since male striped mice tested in winter located the shelter faster in the long-term memory session of the Barnes maze test than males tested in summer. The seasonal differences that we reported are not necessarily due to seasonal changes in cognition but alternatively to seasonal differences in perception, motor performance or motivation. The fact that performance of striped mice did not differ seasonally in the trials where they were exposed to an artificial predator (i.e. bat trials) indicates that spatial learning during the previous neutral trials did not differ between seasons, but that all individuals learned the maze equally well. It is also unlikely that the differences that we reported in the neutral and control trials result from perceptive or motor impairment because the individuals tested in summer were as fast to locate the shelter in the bat trial as the individuals tested in winter. Seasonal differences in motivation better explain the reported seasonal variation in spatial performance because male striped mice tested in summer took longer to poke the correct hole in the control trial than in the bat trials despite a lack of changes in the number of errors. We thus assume that seasonal variation in males' spatial performance result from a higher motivation to locate the shelter during winter. 
Male striped mice might have been more motivated to hide and less motivated to perform exploration during winter because of a necessity to reduce energy expenditure. At the evolutionary level, improved spatial performance in winter may be adaptive in species where males disperse and breed in spring (Galea et al. 1996). In the deer mouse Peromyscus maniculatus, a polygynous seasonal breeder in which mostly the males disperse, spatial performance improves during the breeding season relative to the non-breeding season in males but not females (Galea et al. 1994). Rhabdomys pumilio is also polygynous, and male dispersal starts in winter, several weeks before reproduction in spring (Schradin, unpubl. data). Male striped mice travel distances of up to several kilometers during dispersal to colonize new territories (Solmsen et al. 2011), which is likely to increase demands on spatial learning and memory processing. We thus hypothesize that the enhanced spatial performance is due to greater motivation in male striped mice tested during winter relative to males tested during summer because of male dispersal during this season and the following spring.

\section{Conclusions}

We demonstrated the existence of seasonal variation in attention and spatial performance in male but not female African striped mice. This suggest that winter provides diverse challenges for males and females in this rodent species. In males, the enhanced orientation time is associated with reduced ambient temperature and better spatial performance appears to suggest a greater dispersal motivation before breeding. Females were seasonally unvarying suggesting that they were buffered from thermoregulatary challenges and were under different behavioural motivations of nesting in a colony. The presence of both seasonal and sex differences in cognitive traits that are crucial to avoid predation, suggest that the African striped mouse Rhabdomys pumilio, living in the Succulent Karoo semi-desert of South Africa, could be an ideal rodent model for investigating flexibility in cognition and behavioural motivation under natural and seasonally changing conditions.

\section{Acknowledgments}

This research was supported by a fellowship (to CS) of the University of Strasbourg Institute for Advanced Study. This study was made possible by the administrative and technical support of the Succulent Karoo Research Station (registered South African NPO 122-134), where fieldwork took place. We thank Ivana Schoepf, Chi-Hang Yuen, Patrick Brunner and Andrea Del Mela Gorrino for assistance in data collection. We also thank Bernard Thierry for helpful discussions about the methodology. 


\section{Ethical note}

Animal ethical clearance was provided by the University of the Witwatersrand, Johannesburg, South Africa (no. 2013/50/2A). All procedures were in accordance with the ethical standards of the institution or practice at which the studies were conducted. All applicable international, national, and/or institutional guidelines for the care and use of animals were followed. The authors declare that they have no conflict of interest.

\section{References}

Abrams PA (1994) Should prey overestimate the risk of predation? The American naturalist 144:317328.

Aimé P, Duchamp-Viret P, Chaput MA, et al. (2007) Fasting increases and satiation decreases olfactory detection for a neutral odor in rats. Behavioural Brain Research 179:258-264. doi: 10.1016/j.bbr.2007.02.012

Barnes CA (1979) Memory deficits associated with senescence: a neurophysiological and behavioural study in the rat. J Comp Physiol Psychol 93:74-104.

Bowman RE (2005) Stress-Induced Changes in Spatial Memory are Sexually Differentiated and Vary Across the Lifespan. Journal of Neuroendocrinology 17:526-535. doi: 10.1111/j.13652826.2005.01335.x

Buchanan KL, Grindstaff JL, Pravosudov VV (2013) Condition dependence, developmental plasticity, and cognition: implications for ecology and evolution. Trends in Ecology \& Evolution 28:290-296. doi: 10.1016/j.tree.2013.02.004

Canals M, Rosenmann M, Bozinovic F (1989) Energetics and geometry of huddling in small mammals. J theor Biol 141:181-189.

Chatelain M, Halpin CG, Rowe C (2013) Ambient temperature influences birds' decisions to eat toxic prey. Animal Behaviour 86:733-740. doi: 10.1016/j.anbehav.2013.07.007

Clayton NS, Cristol DA (1996) Effects of photoperiod on memory and food storing in captive marsh tits,Parus palustris. Animal Behaviour 52:715-726. doi: 10.1006/anbe.1996.0216

Clayton NS, Reboreda JC, Kacelnik A (1997) Seasonal changes of hippocampus volume in parasitic cowbirds. Behavioural Processes 41:237-243. doi: 10.1016/S0376-6357(97)00050-8

Cowling RM, Esler KJ, Rundel PW (1999) Namaqualand, South Africa - an overview of a unique winter-rainfall desert ecosystem. Plant Ecology 142:3-21. doi: 10.1023/A:1009831308074

Dal-Pan A, Pifferi F, Marchal J, et al. (2011) Cognitive Performances Are Selectively Enhanced during Chronic Caloric Restriction or Resveratrol Supplementation in a Primate. PLoS ONE 6:e16581. doi: 10.1371/journalpone.0016581 
Ferrari MCO (2014) Short-term environmental variation in predation risk leads to differential performance in predation-related cognitive function. Animal Behaviour 95:9-14. doi: 10.1016/j.anbehav.2014.06.001

Galea LAM, Kavaliers M, Ossenkopp K-P, et al. (1994) Sexually dimorphic spatial learning varies seasonally in two populations of deer mice. Brain Research 635:18-26. doi: 10.1016/00068993(94)91419-2

Galea LAM, Kavaliers M, Ossenkopp KP (1996) Sexually dimorphic spatial learning in meadow voles Microtus pennsylvanicus and deer mice Peromyscus maniculatus. J Exp Biol 199:195-200.

Galea LAM., McEwen B. (1999) Sex and seasonal changes in the rate of cell proliferation in the dentate gyrus of adult wild meadow voles. Neuroscience 89:955-964. doi: 10.1016/S03064522(98)00345-5

Geiser F (2004) Metabolic Rate and Body Temperature Reduction During Hibernation and Daily Torpor. Annual Review of Physiology 66:239-274. doi: 10.1146/annurev.physiol.66.032102.115105

Geiser F, Goodship N \& Pavey CR (2002) Was basking important in the evolution of mammalian endothemy? Naturwissenschaften, 89:412-414.

Gilsenan MB, de Bruin EA, Dye L (2009) The influence of carbohydrate on cognitive performance: a critical evaluation from the perspective of glycaemic load. British Journal of Nutrition 101:941-949. doi: 10.1017/S0007114508199019

Isler K, van Schaik CP (2006) Metabolic costs of brain size evolution. Biol Lett 2:557-560. doi: $10.1098 / \mathrm{rsbl} .2006 .0538$

Jašarević E, Williams SA, Roberts RM, et al. (2012) Spatial navigation strategies in Peromyscus: a comparative study. Animal Behaviour 84:1141-1149. doi: 10.1016/j.anbehav.2012.08.015

Kotrschal A, Taborsky B (2010) Environmental Change Enhances Cognitive Abilities in Fish. PLoS Biol 8:e1000351. doi: 10.1371/journalpbio.1000351

Laughlin SB (2001) Energy as a constraint on the coding and processing of sensory information. Current Opinion in Neurobiology 11:475-480. doi: 10.1016/S0959-4388(00)00237-3

Maille A, Schradin C (submitted) Eco-physiology of cognition: in how far environmentally-induced changes in physiology affect cognitive performance.

McCue MD (2010) Starvation physiology: Reviewing the different strategies animals use to survive a common challenge. Comparative Biochemistry and Physiology Part A: Molecular \& Integrative Physiology 156:1-18. doi: 10.1016/j.cbpa.2010.01.002

Piersma T, Drent J (2003) Phenotypic flexibility and the evolution of organismal design. Trends in Ecology \& Evolution, 18:228-233.

Pillay N, Rymer TL (2015) Alloparenting enhances the emotional, social and cognitive performance of female African striped mice, Rhabdomys pumilio. Animal Behaviour 99:43-52. doi: 10.1016/j.anbehav.2014.10.003

Popović N, Madrid JA, Rol MÁ, et al. (2010) Barnes maze performance of Octodon degus is gender dependent. Behavioural Brain Research 212:159-167. doi: 10.1016/j.bbr.2010.04.005 
Pravosudov VV, Clayton NS (2001) Effects of demanding foraging conditions on cache retrival accuracy in food-caching mountain chickadees (Poecile gambeli). Proc Biol Sci 268:363-368. doi: $10.1098 / \mathrm{rspb} .2000 .1401$

Pyter LM, Trainor BC, Nelson RJ (2006) Testosterone and photoperiod interact to affect spatial learning and memory in adult male white-footed mice (Peromyscus leucopus). European Journal of Neuroscience 23:3056-3062. doi: 10.1111/j.1460-9568.2006.04821.x

Raynaud J, Schradin C (2013) Regulation of male prolactin levels in an opportunistically breeding species, the African striped mouse. Journal of Zoology 290:287-292. doi: 10.1111/jzo.12040

Rodriguiz RM, Wetsel WC (2006) Assessments of Cognitive Deficits in Mutant Mice. Animal Models of Cognitive Impairment .

Romero LM (2002) Seasonal changes in plasma glucocorticoid concentrations in free-living vertebrates. General and Comparative Endocrinology 128:1-24. doi: 10.1016/S00166480(02)00064-3

Rosch H (2001) The identification and description of the management units of the Goegap Nature Reserve. Koedoe 44:17-30.

Roth TC, Brodin A, Smulders TV, et al. (2010) Is bigger always better? A critical appraisal of the use of volumetric analysis in the study of the hippocampus. Phil Trans R Soc B 365:915-931. doi: 10.1098/rstb.2009.0208

Rymer T, Schradin C, Pillay N (2008) Social transmission of information about novel food in two populations of the African striped mouse, Rhabdomys pumilio. Animal Behaviour 76:12971304. doi: 10.1016/j.anbehav.2008.06.014

Scantlebury M, Bennett NC, Speakman JR, Pillay N, Schradin C (2006) Huddling in groups leads to daily energy savings in free-living African four-striped grass mice, Rhabdomys pumilio. Funct Ecol 20:166-173.

Scantlebury M, Krackow S, Pillay N, Bennett N, Schradin C (2010) Basking is affected by season and influences oxygen consumption in desert-living striped mice. Journal of Zoology, 281, 132139.Schradin C (2006) Whole-day follows of striped mice (Rhabdomys pumilio), a diurnal murid rodent. J Ethol 24:37-43. doi: 10.1007/s10164-005-0158-2

Schradin C, Krackow S, Schubert M, et al. (2007) Regulation of activity in desert-living striped mice: The importance of basking Ethology 113:606-614.

Schradin C, Lindholm AK (2011) Relative fitness of alternative male reproductive tactics in a mammal varies between years. Journal of Animal Ecology 80:908-917. doi: 10.1111/j.13652656.2011.01831.x

Schradin C, Pillay N (2005) Demography of the striped mouse (Rhabdomys pumilio) in the succulent karoo. Mammalian Biology - Zeitschrift für Säugetierkunde 70:84-92. doi: 10.1016/j.mambio.2004.06.004

Schradin C, Pillay N (2006) Female striped mice (Rhabdomys pumilio) change their home ranges in response to seasonal variation in food availability. Behavioural Ecology 17:452-458. doi:10.1093/beheco/arj047 
Sherry DF, Hoshooley JS (2009) The seasonal hippocampus of food-storing birds. Behavioural Processes 80:334-338. doi: 10.1016/j.beproc.2008.12.012

Solianik R, Skurvydas A, Mickevičienė D, Brazaitis M (2014) Intermittent whole-body cold immersion induces similar thermal stress but different motor and cognitive responses between males and females. Cryobiology 69:323-332. doi: 10.1016/j.cryobiol.2014.08.007

Solmsen N, Johannesen J, Schradin C (2011) Highly asymmetric fine-scale genetic structure between sexes of African striped mice and indication for condition dependent alternative male dispersal tactics. Molecular Ecology 20:1624-1634. doi: 10.1111/j.1365-294X.2011.05042.x

Tramontin AD, Brenowitz EA (2000) Seasonal plasticity in the adult brain. Trends in Neurosciences 23:251-258. doi: 10.1016/S0166-2236(00)01558-7

Yanai S, Okaichi Y, Okaichi H (2004) Long-term dietary restriction causes negative effects on cognitive functions in rats. Neurobiology of Aging 25:325-332. doi: 10.1016/S01974580(03)00115-5

Yaskin VA (2011) Seasonal changes in hippocampus size and spatial behaviour in mammals and birds. Biol Bull Rev 1:279-288. doi: 10.1134/S2079086411030108

Yaskin VA (2013) Seasonal modulation of sex-related differences in hippocampus size and spatial behaviour in bank voles, Clethrionomys glareolus (Rodentia, Cricetidae). Russ J Ecol 44:221226. doi: $10.1134 / \mathrm{S} 1067413613030156$ 
Reserve, Northern Cape, South Africa) during the study period.

\begin{tabular}{|c|c|c|c|c|c|c|}
\hline & Tmin & Tmax & Rain & Pplants & Nfood & Popufation \\
\hline Jan & 8.8 & 42.6 & 22.2 & 16.2 & 4.4 & 240 \\
\hline Feb & 9.5 & 43.2 & 0.7 & 14.6 & 2.3 & 228 \\
\hline Mar & 5.3 & 42.9 & 17.2 & 14.3 & 1.6 & 196 \\
\hline Apr & 5.8 & 37.4 & 3.7 & 13.5 & 2.1 & 178652 \\
\hline May & 3.9 & 35.9 & 5.9 & 12.7 & 3 & 164 \\
\hline Jun & 0.7 & 27.8 & 35.7 & 13.1 & 3.6 & 147 \\
\hline Jul & -0.1 & 27.1 & 22.1 & 15.3 & 5.4 & 119 \\
\hline
\end{tabular}

Notes. Tmin: average daily minimum temperature in ${ }^{\circ} \mathrm{C}$, Tmax: average daily maximum temperature in ${ }^{\circ} \mathrm{C}$, Rain: total precipitation in mm, Pplants: Percentage of area covered by plants, Nfood: mean number of green food plant species, Population: total number of trapped individuals in the population. Data for Pplants and Nfood were collected twice a month in 8 distinct $4 \mathrm{~m}^{2}$-plots (Schradin and Pillay 2006). Summer months of the study are marked in light grey shading, winter months in dark grey shading.

Table 2. Body mass and metabolic indicators measured 5 to 20 days before cognitive testing in the striped mice tested in summer and winter (mean \pm SE).

674

\begin{tabular}{lcccc}
\hline & Summer $(\mathrm{N}=64)$ & Winter $(\mathrm{N}=42)$ & t-test $(\mathrm{p} \text {-val6] })^{5}$ \\
\hline Body mass $(\mathrm{g})$ & $36.3 \pm 1.1$ & $38.1 \pm 1.3$ & 0.310 & 676 \\
Blood glucose $(\mathrm{mmol} / \mathrm{L})$ & $5.7 \pm 0.2$ & $6.3 \pm 0.4$ & 0.130 & 677 \\
Ketone bodies $(\mathrm{mmol} / \mathrm{L})$ & $0.5 \pm 0.0$ & $0.5 \pm 0.0$ & 0.460 & 678 \\
Basal corticosterone $(\mathrm{ng} / \mathrm{mL})$ & $\mathbf{7 5 3 . 4} \pm \mathbf{4 3 . 6}$ & $\mathbf{5 5 6 . 7} \pm \mathbf{4 8 . 8}$ & $\mathbf{0 . 0 1 1} * 680$ \\
\hline
\end{tabular}

Notes. Significant seasonal differences are marked in bold $\left({ }^{*} \mathrm{p}<0.05\right)$ 


\section{Figure captions}

Fig. 1 Orientation time in seconds (means + SE) for the first orientation response toward the raptor-stimulus in the orientation response test in males (left) and females (right). A total of 80 individuals were tested: individuals tested during summer are depicted in dark grey (males: $\mathrm{N}=23$, females: $\mathrm{N}=22$ ) and individuals tested during winter in light grey (males: $\mathrm{N}=16$, females: $\mathrm{N}=19$ ).* $\mathrm{p}<$ 0.05 .

Fig. 2 Number of errors (black line) and latency in seconds to poke the correct hole (dash line) for each trial of the short-term memory (left) and long-term memory (right) sessions of the Barnes maze test, depicted as means \pm SE. A total of 89 individuals were tested. The long-term memory session occurred $8 \pm 3$ days after the short-term memory session. Trials N1 to N6 were neutral trials, trials B1 and B2 were bat trials (animated predator-like toy above the maze) and trial C was a control trial (no escape box); trials were separated from one other using a 5-minute delay. The results of the pairwise-t-tests (number of errors: $a \neq b \neq c, p<0.05$; latency: $\alpha \neq \beta \neq \gamma \neq \delta, p<0.05$ ) allowed us to group the trials in 4 distinct categories: the N-I category consisting of trials N1 and N2, the N-II category consisting of trials N3, N4, N5 and N6, the Bat category consisting of trials B1 and $\mathrm{B} 2$ and the Control category consisting of the trial C.

Fig.3 Latency in seconds to poke the correct hole depicted as means for each trial of the shortterm memory (left) and long-term memory (right) sessions of the Barnes maze test, in each sex and for each season. A total of 89 individuals were tested: individuals tested during summer are depicted with a full line (males: $\mathrm{N}=26$, circles; females: $\mathrm{N}=22$, triangles) and those tested during winter with a dashed line (males: $\mathrm{N}=25$, circles; females: $\mathrm{N}=16$, triangles). The long-term memory session occurred $8 \pm 3$ days after the short-term memory session. Trials N1 to N6 were neutral trials, trials B1 and B2 were bat trials (animated predator-like toy above the maze) and trial C was a control trial (no escape box); trials were separated from one other using a 5-minute delay.

Fig. 4. Spatial performance of males for the Neutral-I, Neutral-II, Bat and Control categories of trials of the long-term memory session in the Barnes maze test: (a) Number of errors (mean + SE) and (b) latency to poke the correct hole in seconds (mean + SE). A total of 51 males were tested: individuals tested during summer are depicted in dark grey $(\mathrm{N}=26)$ and those tested during winter in light grey $(\mathrm{N}=25) ; * *: \mathrm{p}<0.01, * * *: \mathrm{p}<0.001$. 
Fig. 5. Spatial performance of females for the Neutral-I, Neutral-II, Bat and Control categories of trials of the long-term memory session in the Barnes maze test: (a) Number of errors (mean + SE) and (b) latency to poke the correct hole in seconds (mean + SE). A total of 38 females were tested: individuals tested during summer are depicted in dark grey $(\mathrm{N}=22)$ and those tested during winter are depicted in light grey $(\mathrm{N}=16)$.

\section{$\underline{\text { Electronic supplementary material captions }}$}

Online resource 1: Orientation response test.

742

A mouse (identified with ear tags and red/blonde hair dye) placed in a transparent box facing a white screen, orients its head towards the raptor-stimulus that appeared at the left-bottom of the screen and slides in a rightward motion. The raptor-stimulus presentation lasts 5 seconds.

Online resource 2: Barnes maze test - Bat trial

A mouse (placed in transparent circular box at the center of the Barnes maze) is released, nose-pokes 4 incorrect holes and then locates the correct hole providing access to an escape box. A bat toy hanging above the maze mimics the presence of a flying predator. Pictures of rocks and plants (photographed in the natural habitat of the population of mice tested) that are placed on the walls and curtains surrounding the maze provide visual landmarks to the mice. 